\title{
Hacia una planificación en tiempo real
}

Alejandro Blanch

Director de Planificación de Mediterránea

Estemos donde estemos, siempre llevamos en nuestro bolsillo una ventana abierta hacia el mundo. Vivimos permanentemente conectados y nos movemos en un ambiente cada vez más digital.

En este entorno, los medios han de afinar aún más sus estrategias y transformar el concepto tradicional de planificación si quieren llegar a unas audiencias enormemente fragmentadas. La planificación dependerá de una organización y unos procesos excelentes, cierto, pero, cada vez más, del correcto manejo de los datos mediante la tecnología adecuada. Hablamos de Big Data, de gestión de unos datos que son esenciales para las campañas y fundamentales cuando una empresa o marca te confía su cartera de inversión.

Pero esa tecnología y esos datos no servirán de nada si no se cuenta con talento capaz de manejarlos. Es necesario que haya nuevos perfiles profesionales con un carácter altamente analítico, que sepa sacar el mejor partido de esa información para un mejor conocimiento del consumidor. Y ese es el camino que las agencias de medios hemos emprendido, incorporando talento analítico y multidisciplinar, capaz de entender y enlazar marcas, audiencias y medios de una forma más sensorial y eficaz.

Este entendimiento, sumado a una buena base de segmentación, uno de los mayores objetivos de la planificación será estar pegados al tiempo real de cada consumidor y de los medios, al Real Time. Y es que cada punto de contacto, a través de ese viaje del usuario hacia la marca, aportará una información crucial que finalmente se convertirá en un retorno de la inversión. Aquí es donde entra nuestra función como planificadores y estrategas: dar valor a esa inversión.

Para conseguirlo de forma óptima se tendrán que aplicar los conceptos mencionados, como talento, Big Data, tecnología y segmentación, junto con el diseño de creatividades dinámicas que se ajusten a cada usuario, adaptando los mensajes de forma continua... Hablo de Real Time Bidding, que marcará el futuro 
de una planificación que se hará en tiempo real y personalizada, a medida para cada cliente.

Para que una agencia sea de Real Time ha de observar y analizar en tiempo real. Sólo así se conseguirá colocar los mensajes más adecuados en el lugar preciso para el consumidor, de forma que la acción sea realmente eficaz. El Real Time Bidding aboga por la transparencia, con el fin de saber dónde se compran las campañas y a qué precios; junto a esto, por supuesto, la tecnología, con campañas optimizadas; y con un servicio totalmente adaptado al cliente.

Pese a los momentos de dificultades que nos rodean, vivimos en un período apasionante, de plena transformación del sector y por tanto hemos de estar preparados. Cada día aparecen nuevos medios y se abren nuevas posibilidades para la comunicación. Hoy en día manda el consumidor, es quien tiene la capacidad de elegir entre una marca u otra. Este es el reto de la planificación, llegar a él en tiempo real con mensajes que le interesen, que le aporten valor a su vida a la vez que aumenta el de la marca.

\section{Referencia de este artículo}

Blanch, Alejandro (2014). Hacia una planificación en tiempo real. En: adComunica. Revista Científica de Estrategias, Tendencias e Innovación en Comunicación, $n^{0} 7$. Castellón: Asociación para el Desarrollo de la Comunicación adComunica, Universidad Complutense de Madrid y Universitat Jaume I, 203-204. DOI: http://dx.doi.org/10.6035/2174-0992.2014.7.13. 